\title{
A Basic Classification of Legal Institutions
}

DICK W. P. RUITER*

Abstract. The author offers a general definition of legal institutions. A distinction between institutional legal concepts, legal institutions and social institutions makes it possible to define legal institutions as systems of valid presentations of what must occur in social reality in order that the former can be said also to exist as social institutions. Weinberger's idea, that the relation of legal institutions (practical information) to reality is the exact reverse of that between propositions (theoretical information) and reality, is subsequently used in developing a basic classification of legal institutions by analogy with the traditional division of elements of singular propositions in definite descriptions, properties and relations.

\section{Legal Institutions: Three Modes of Existence}

Until recently, positivist legal theory, in the tradition of Kelsen and Hart, was primarily concerned with the analysis of legal orders as systems of rules of conduct that derive their validity from decisions made by applying authorizing rules. This approach has significantly contributed to our understanding of the systemic validity of legal rules (Wróblewski 1992, 77-8). However, the emphasis on the validity of single legal rules was accompanied by a remarkable neglect of the classical doctrinal conception of legal orders as systems of institutions that include rules of conduct and authorizing rules but are not reducible to them. Legal institutions have only recently appeared on the agenda of positivist legal theory. An important impulse was given by MacCormick and Weinberger's outline of an "institutional theory of law" (ITL), in which legal institutions are conceived as "conceptual building blocks" of legal orders (MacCormick and Weinberger 1986; Weinberger 1991, 160).

Bengoetxea observes that it is difficult to give a definition of "legal institutions" on the ground that the term marks family resemblance (Bengoetxea 1991, 196). It is indeed less than easy to give a clear-cut definition covering

* The author wishes to thank Stanley L. Paulson for his invaluable comments.

(c) Blackwell Publishers Ltd 1997, 108 Cowley Road, Oxford OX4 1JF, UK and 350 Main Street, Malden, MA 02148, USA. 
all possible institutions. On the other hand, in institutional legal theory, as well as in various institutional branches of the social sciences-such as institutional economics, public choice oriented theories in political science, and institutional sociology - there appears to be general agreement on a broad conception of institutions as systems of rules that provide frameworks for social action within larger rule-governed settings (Ostrom 1986; Ruiter 1994). Although the aforementioned institutional branches of the social sciences are mainly interested in "institutions for collective action" or "political institutions," they also acknowledge the existence of institutions regulating social activities of individuals, such as "marriage," "property" and "contract" (Ostrom 1990; March and Olsen 1989). On this score, institutions can be roughly characterized as systems of rules governing specific social action in the context of a comprehensive social order. If such systems consist of rules that derive their validity from a legal order, they are legal institutions. The hallmark of legal institutions is that they can be dealt with as distinct social phenomena. Corporations, rights of property, public authorities and contracts are all systems of legal rules that participate, as it were, in social reality as if they existed in a physical sense. How are systems of rules conceivable as existent? A brief analysis of an example provides a useful starting point in answering this question.

When we speak of a particular legal association as an existent social agent, we actually refer to a practice in which an instance of the legal concept "association" is realized. The practice in question amounts to certain individuals acting as the association, while other individuals both acknowledge the acts of the former as stemming from the association and expect certain of their own acts directed towards the first-mentioned individuals to be generally acknowledged as acts directed towards the association. The practice realizes the legal association insofar as it provides a picture of regular social conduct corresponding to the "ideal" image conveyed by the legal rules that together make up the association. As a system of legal rules, the association exists in virtue of its foundation, which in turn came about by appeal to a statutory regulation. In this regulation "association" is recognized as an existent legal concept. Furthermore, the regulation determines how individual associations can be founded and dissolved. Finally, it determines the legal regimes governing individual associations.

The example shows that the mode of existence of legal institutions is complex. In the first place, a legal institution can be said to exist within the legal order as a type (the concept of association). In the second place, a legal institution can be said to exist by virtue of the legal order as a token (a founded association). In the third place, a legal institution can be said to exist as a practice in accordance with a token (an operative association).

Each of these specific modes of existence, as well as their mutual relations, requires further analysis. I shall begin with an examination of the mode of existence of institutional legal concepts. 


\section{Institutional Legal Concepts}

Institutional legal concepts rest on constitutive rules. However, constitutive rules of such concepts are of a special kind. In Searle's well-known description, constitutive rules are of the form " $X$ counts as $Y$ in context $C$ " (Searle 1969, 35 and 52). As an example of a non-legal constitutive rule, Searle offers the rule for checkmate: "A checkmate is made when the king is attacked in such a way that no move will leave it unattacked" (Searle 1969, 34). According to Searle, constitutive rules underlie such institutional facts as checkmating. Unlike the existence of "brute" physical facts, the existence of institutional facts presupposes the existence of certain human institutions. Searle conceives of such institutions as systems of constitutive rules (Searle 1969, 51).

Obviously, in the same manner as the concept "checkmate" exists, namely, by virtue of the constitutive rule of checkmate, the concept "association" exists by virtue of the constitutive legal rule of association. There is, however, a complication. Whereas the constitutive rule of checkmate underlies a category of institutional facts — cases of checkmate - the constitutive legal rule of "association" underlies a category of institutions - associations. Institutions are indeed conceivable as complex institutional facts, but they are, first and foremost, institutions providing contexts that serve to "place" or "locate," as it were, other institutional facts. The constitutive rule of an institutional legal concept, therefore, differs from, for instance, the constitutive rule of "checkmate" in that the former provides a general outline of certain specific systems of rules that can come into existence in the context of the legal order, instead of a specification of singular institutional facts.

Constitutive rules of institutional legal concepts underlie a category of legal systems. Such a category is created in the form of a legal recognition of the name of its members as the designation of a valid legal concept. For the most part, this name is already in use in the legal community ahead of its recognition as the designation of a legal concept. Most institutional legal concepts are, originally, social notions that have subsequently received legal recognition. However, there also exist institutional legal concepts that are the result not of legal reception but of legal design.

Partly owing to the varied origins of institutional legal concepts, the ways in which their constitutive rules are included in the legal order differ. The existence of the constitutive rules of some institutional legal concepts can be conjectured only from the fact that their name is actually used in the legal order. For instance, the Dutch Civil Code does not provide an explicit constitutive rule of marriage but simply uses the term. Other institutional legal concepts rest on legal rules that explicitly acknowledge them as valid but fail to specify what they stand for. For example, art. 123 of the Dutch Constitution provides that local communities can be established and dissolved, but the Dutch legal order does not include a specification of "local community." Still other institutional legal concepts rest on constitutive rules defining them. An 
example is offered by the constitutive rule of "public limited company": "The public limited company is a legal person with an authorized capital that is divided into transferable shares" (Art. 2: 64 Dutch Civil Code).

Respecting Searle's account of constitutive rules in general, it would seem that the constitutive rule of an institutional legal concept must have the form of a specification of the act whose performance brings about instances of the concept. In Searle's standard example: "To make a promise is to undertake an obligation," the constitutive rule of the institutional concept "promise" is actually a specification of the act of promising (Searle 1969, 63 and 179; Conte 1986, 46). With respect to those instances of institutional legal concepts that can only be created by the performance of a single act, one can say that such concepts (types) are constituted by specifying how their instances (tokens) are created. In such cases the institutive rules in the sense proposed by MacCormick, that is, as rules laying down that the occurrence of a certain act (or event) triggers a specific instance of a legal institution, coincide with the constitutive rules (MacCormick and Weinberger 1986, 52-3; Ruiter 1993, 208).

A major objection to this view, namely, that the two types of rule coincide in this manner and can therefore be identified with each other, is that instances of many institutional legal concepts can come into existence in different ways. Of course, this objection can be met by introducing constitutive rules that include disjunctive enumerations of institutive acts. This solution, however, discards the pragmatic advantages of differentiating between constitutive rules of institutional legal concepts and institutive rules of their instances. As Ross has pointed out, this differentiation makes it possible to represent systematic connections between "conditioning facts" and "legal consequences" of legal rules in a manageable way (Ross 1958, 170-72; Ruiter 1993, 209-11). An example will illustrate Ross's point.

Suppose that a certain legal order recognizes two ways in which property can be acquired: conveyance and succession, and that it also recognizes two legal consequences of such an acquisition: exclusive right of use and right of reclamation. The systematic connections between the two conditioning facts and the two legal consequences can be represented as follows:

1) conveyance $\longrightarrow$ use

3) conveyance $\rightarrow$ reclamation
2) succession $\rightarrow$ use

4) succession $\rightarrow$ reclamation

Even with respect to a small set of rules such as this, a systematization with the help of the institutional legal concept "ownership" is considerably less complex:

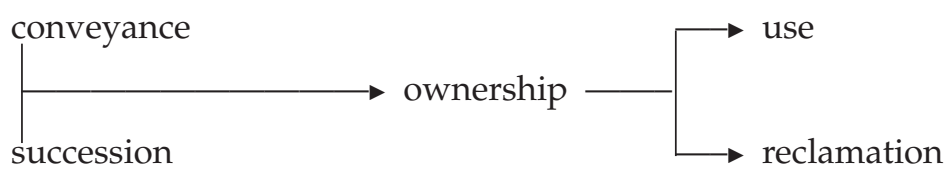

(c) Blackwell Publishers Ltd 1997. 
The advantages of this method for making extensive systems of conditioning facts and legal consequences manageable would be lost if the constitutive rules of institutional legal concepts were assimilated to the sets of rules that determine the ways in which instances of them can come into existence. Moreover, a differentiation between both kinds of rules greatly facilitates the changing of the ways in which legal institutions can come into existence without changing the institutional legal concept in question.

Given this division of labour between constitutive rules and institutive rules, the role of the former is reduced to laying down that a certain term designates an institutional concept of the legal order. Needless to say, to be effective a constitutive rule must be accompanied by at least one institutive rule specifying an act whose performance brings about instances of the institutional legal concept in question.

According to MacCormick, regulations of institutional legal concepts include two further kinds of rules, namely terminative rules and consequential rules. Terminative rules are the counterparts of institutive rules. They specify acts whose performance terminates the legal existence of instances of an institutional legal concept. According to MacCormick, "for each institution there is a set of rules of which an operative fact is that an instance of the institution exists." Such rules are termed "consequential rules" (MacCormick and Weinberger 1986, 52-3; Ruiter 1993, 208). Consequential rules provide an outline of the legal regimes of such instances, that is, of legal institutions falling within the category designated by the institutional concept.

\section{Legal and Social Institutions}

For the purpose of clarifying how the regimes of legal institutions are built up and what objectives they serve, it is useful to consider an important distinction between two kinds of information that regulate human action. It is the distinction between theoretical and practical information drawn by Weinberger on the basis of Searle's criterion of "direction of fit" between "word" and "world" (Searle 1979, 3 and 12; Searle and VanderVeken 1985, 28; VanderVeken 1990, 105; Weinberger 1991, 215; Ruiter 1993, 48 and 214-15).

Theoretical information purports to represent the facts as they are. Accordingly, theoretical information is either true or false. With respect to theoretical information, its truth counts as a positive value and its falsity as a negative value of the information. The direction of fit between word (information) and world (the facts) is therefore "word-to-world." On the other hand, practical information purports to present the facts as they ought to be. Accordingly, practical information is fit to be made true by men. With respect to practical information, conformity between information and facts counts as a positive value of the facts, whereas an incongruity between both likewise counts as a negative value of the facts. The direction of fit between word (information) and world (the facts) is therefore "world-to-word." 
The difference is visualized in the scheme below.

Theoretical Information

Representations

Practical Information

Presentations
Direction of Fit

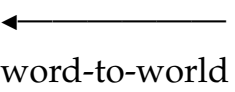

Direction of Fit

world-to-word
Reality

Facts

Reality

Facts

The upper arrow indicates that where theoretical information is concerned, the facts provide the criterion for judging the representations of which the information consists. Conversely, the bottom arrow indicates that where practical information is concerned, the presentations of which the information consists provide the criterion for judging the facts to which the presentations relate.

On Weinberger's view, legal institutions provide practical information in the form of valid presentations serving as criteria for adapting social reality. This view makes it possible to conceive of legal institutions as standards of social interaction that are not reducible to mandatory rules. For it warrants the distinction between the question whether or not legal institutions are realized in corresponding practices on the one hand, and the question which agents are responsible for possible divergences on the other.

A legal institution regulates social conduct inasmuch as the valid picture it provides purports to effectuate a social practice yielding a corresponding picture. For example, the lawful marriage of John and Mary is a legal institution that provides a valid picture of John and Mary as being married with the purpose of effectuating a social practice that offers an actual picture of John and Mary living the life of a married couple. The practice required to realize John and Mary's marriage is not restricted to their fulfilling their marital duties but also includes recognition of their marriage by the legal community at large, including its officials, in all relevant circumstances.

As valid instances of an institutional legal concept, legal institutions present the legal community with rough outlines of the practices to be established. The details of the practices are further determined by the legal regimes of the institutions. Such institutional legal regimes follow from the consequential rules laid down in the statutory regulation of the institutional legal concept in question.

The legal regime of a legal institution can be defined as the set of legal consequences that flow from the existence of the institution. However, the meaning of "legal consequences" is different from what is normally understood by the term. In general, a legal rule is thought to consist of two related parts. The first part specifies the facts to which the rule applies (operative facts), whereas the second part determines the norms that apply to occurrences of 
these facts (legal consequences). Legal consequences are conceived as categorical norms. The rule "Drivers shall keep to the left side of the road" applies to all cases of driving on the road. In these cases there is a categorical obligation to keep to the left side of the road. In contrast, legal consequences of the existence of legal institutions are, once again, legal rules. For example, the legal rule "Parents have the reciprocal obligation to take care of and support their children" applies to all marriages. The legal consequence of this rule for a certain marriage is not a categorical obligation but the legal rule that each time the parents in question have a child they are under the obligation to take care of and support that child. In this way consequential rules provide for the coming into existence of legal rules that make up the regimes of legal institutions.

A legal institution together with its regime is a system of valid presentations of states of affairs and activities that must occur in social reality in order that the institution can be said to exist, too, as a social institution. The system determines the institution's objectives, its internal and external organization, and the ways in which it can be developed. Thus, it provides an elaborate picture of a practice that counts as the corresponding social institution. Accordingly, a social institution is a collection of social relationships that is treated as a distinct social phenomenon because it is organized in conformity with the overall picture presented by a valid legal institution and its regime.

\section{A Classification of Legal Institutions}

A legal institution is a presentation of a phenomenon that, in a word, ought to be made true. The presentation is actually made true in the form of a social practice that recognizes the phenomenon presented. It is important to see that a legal institution is in the first instance a fiction that is subsequently realized by people believing in it and acting upon this belief. It follows i) that human beings must be able to visualize legal institutions and ii) that the existence of legal institutions must be conceivable as inherent in human behaviour. To be sure, both of these conclusions touch on profound philosophical problems going far beyond the scope of this paper. It is therefore advisable to take an approach that, admittedly at the price of oversimplification, makes it possible to steer clear of such problems. The approach has its point of departure in the idea that the relationship between practical information and reality is the exact reverse of that between theoretical information and reality. Given an exposition of the terms in which theoretical information represents singular facts, we could examine these same terms with respect to their suitability for presenting the envisioned phenomena that are to be realized by social behaviour.

In representing particular entities, theoretical information employs individual concepts. Individual concepts are designates of proper names ("the Eiffel tower") or of definite descriptions ("the 300-metre-high steel tower in 
Paris"). Individual concepts serve as arguments to which attributes can be predicated. Attributes represent properties ("The Eiffel tower is grey") or relations ("The Eiffel tower is near the Louvre"). Finally, within the category of entities a distinction can be made between subjects and objects. Subjects can perform acts, objects cannot. Theoretical information turns out to be structured according to a conception of reality as consisting of entities (objects and subjects) on the one hand, and qualities (properties and relations) on the other. This conception serves as the basis of a classification comprising seven fundamental categories of representations of particular phenomena:

i) Representations of particular subjects (Churchill; the virgin of Orléans).

ii) Representations of particular objects (Stonehenge; the sixth wonder of the world).

iii) Representations of particular subjects having certain properties (Clinton is grey; this man is tall).

iv) Representations of particular objects having certain properties (the Eiffel tower is grey; this house is old).

v) Representations of particular subjects having certain relations (John is William's father; that man and woman are a couple).

vi) Representations of particular objects having certain relations (the Louvre is near the Eiffel tower; the house is opposite the station).

vii) Representations of particular subjects having certain relations to particular objects (Clinton lives in the White House; the man loves his car).

The intriguing question is whether this classification can also be used to distinguish basic categories of legal institutions. To answer this question we must first examine whether legal institutions can, in principle, be conceived as individual concepts or predicates.

When an individual concept occurs in theoretical information, it purports to refer to an entity that exists, has existed or will exist. When a predicate occurs in theoretical information, it ascribes to the entity or entities to which it refers an attribute representing an actual property of the former. In contrast, a legal individual concept does not refer to an existent entity, but aims at bringing about certain behavioural relations in consequence of a generally accepted fiction to the effect that it refers to an existent entity. Likewise, the entity or entities to which a legal predicate refers do not have the ascribed property, but the predicate aims at bringing about certain behavioural relations in consequence of a generally accepted fiction to the effect that the entity or entities concerned have the property in question. Legal individual concepts or predicates can be said to exist in a metaphorical sense insofar as the behavioural relations they purport to effectuate actually do occur. However, the mode of existence in question is that of a pattern of behaviour 
governed by a socially accepted fiction (Olivecrona 1971, 217-30; Rowe 1989, 5, 22, 60 and 78; Ruiter 1993, 5-8). This means that an existent legal institution answers to the following scheme:

Legal Order

legal

institution
Direction of Fit recognition

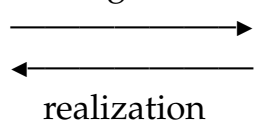

Social Reality

pattern of behaviour

Provided that it be kept in mind that legal institutions do not exist in a physical sense, it appears that the foregoing classification of theoretical information can be transformed into a classification of legal institutions conceived as valid presentations that ought to be made true. The result of the transformation is set out in the following scheme.

Classification of Legal Institutions

Legal Persons: A legal person is a valid presentation of a person (The Red Cross).

Legal Qualities: A legal quality is a valid presentation of a characteristic of a person (John's minority).

Legal Status: A legal status is a valid presentation of a property of an object (Yellowstone National Park).

Personal Legal Relations: A personal legal relation is a valid presentation of a relation between persons (John and Mary's community property).

Legal Configurations: A legal configuration is a valid presentation of a relation between objects (Great Britain's territorial sea).

Objective Legal Relations: An objective legal relation is a valid presentation of a relation between a person and an object (John's ownership of the house he lives in).

Legal Objects: A legal object is a valid presentation of an object (John's transferable right).

The separate classes will be examined more closely below.

\section{Classes of Legal Institutions}

\section{Legal Persons}

A legal person is a valid presentation of an entity that is capable of acting. The definition implies not that the legal person itself, but rather the entity 
it presents, is conceived as capable of acting. Such an entity is a system of behavioural relations making the legal person true. The system is further specified by the legal regime of the legal person. The regime imputes the results of performances of certain acts by certain natural persons to the system. Furthermore, it specifies the boundaries of the system, so that a distinction can be made between behavioural relations that are part of the system on the one hand, and behavioural relations between the system and the surrounding legal community on the other. Legal persons make it possible to ascribe aggregate outcomes of collective decision-making processes to the collectivity of the participants.

Legal Order
legal
person

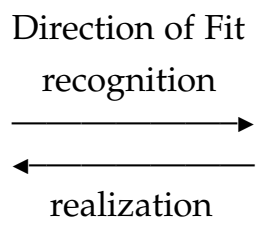

Social Reality

recognized impersonal agent

\section{Legal Qualities}

A legal quality is a valid presentation of a characteristic of a person. Its purpose is that the person presented as having a certain characteristic will be generally dealt with as if he possessed it. The legal consequences of a legal quality are specified by its legal regime. Thus, it follows from the Dutch Civil Code that a person who has not yet reached the age of eighteen years and neither is nor has been married is presented as "under age," with the consequence that he is incapable of performing civil legal acts. The realization of the characteristic presented by the legal quality "under age" requires a social practice of denying certain responsibilities to an unmarried person under eighteen.

$\begin{array}{lll}\text { Legal Order } & \begin{array}{l}\text { Direction of Fit } \\ \text { recognition } \\ \text { quality }\end{array} & \begin{array}{l}\text { Social Reality } \\ \text { recognized characteristic } \\ \text { of a person }\end{array}\end{array}$

\section{Legal Status}

A legal status is a valid presentation of a property of an object. Its purpose is that the object presented as having a certain property will generally be treated as if it possessed the property. The legal regime applying to a legal status determines what behavioural relations are called for to realize the property it presents. Thus, a decision to list a building as a national monument places the building under a legal regime prohibiting harmful activities 
and requiring preservation measures. By putting the legal regime into practice the building's legal status as a national monument is made true. The building counts as a national monument when it is so listed, but it is a national monument only when it is so treated.

\section{Legal Order}

legal

status
Direction of Fit recognition

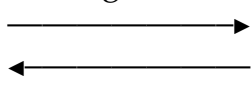

realization
Social Reality

recognized property of an object

\section{Personal Legal Relations}

A personal relation is a set of expectations of persons about reciprocal behaviour. Accordingly, a personal legal relation is a valid presentation of a set of expectations of persons about reciprocal behaviour. Its purpose is that the persons whose mutual relation it presents are regarded by all, including themselves, as having this relation. The presentation is made true when all parties concerned live up to the presented expectations of the other parties. The expectations are specified in the relation's legal regime and supplemented with means to enforce them if they are not spontaneously made true by a party. Thus, a personal right is a valid presentation of a person's expectation that another person will perform some act. The right is made true when the other person considers himself bound to perform the act spontaneously or is duly forced to perform it or to make amends for failing to perform it.

Legal Order

personal

legal relation

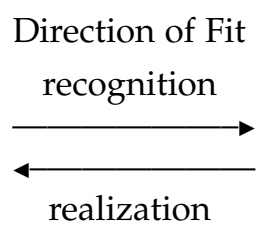

realization
Social Reality

recognized expectations of parties

\section{Legal Configurations}

A legal configuration is a valid presentation of a relation between objects. Its purpose is that the objects presented as having a relation will be generally treated as if they had the relation. For example, an easement is a relation between a servient tenement and a dominant tenement consisting in a burden (e.g., a right of way) laid on the former for the benefit of the latter. The legal regime of the easement specifies that all successive owners of the servient tenement are bound to bear the burden and that all successive owners of the dominant tenement are justified in believing that the former are thus bound. 


\author{
Legal Order \\ legal \\ configuration
}

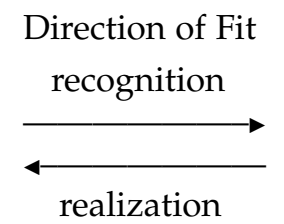

Social Reality

recognized relation

between objects

\section{Objective Legal Relations}

An objective legal relation is a valid presentation of a relation between a person and an object. Its purpose is that the person presented as having the relation to the object will be generally dealt with as if he had that relation to the object. The legal consequences of the legal relation are specified in its legal regime. For example, a right of ownership of real estate presents a person as being in possession of the real estate. By virtue of the legal regime the owner is entitled to prohibit actions of others interfering with his free use of the real estate. Moreover, the owner can reclaim the real estate from any other person who is in actual possession of it.

\section{Legal Order \\ objective legal \\ relation}

Direction of Fit recognition

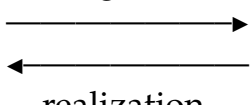

Social Reality

recognized bond between

a person and an object

\section{Legal Objects}

A legal object is a valid presentation of an entity that can serve as an object of the performance of certain acts. The definition implies that it is not the legal object itself, but the entity it presents that is conceived as an object. Such an entity is a system of behavioural relations making the legal object true. The system is further specified by the legal regime of the legal object. The regime determines the acts the system can be an object of and the persons capable of performing these acts.

Legal objects make it possible to deal with systems of behavioural relations as if they were unified objects of human action. Systems of behavioural relations that qualify as unified objects of human action are those realizing legal institutions. In other words, legal objects are legal institutions conceived as "transactionable" entities. For example, a conveyable right of ownership of real estate is in the first place an objective legal relation, that is, a valid presentation of the person possessing the estate. In the second place, it is a legal object because it is also a presentation of the person's possession of the estate as fit to be transferred by him to another person. 


$\begin{array}{lll}\text { Legal Order } & \begin{array}{l}\text { Direction of Fit } \\ \text { recognition }\end{array} & \begin{array}{l}\text { Social Reality } \\ \text { legal } \\ \text { object }\end{array} \\ { } } & \begin{array}{l}\text { recognized transaction- } \\ \text { ability of institution }\end{array}\end{array}$

\section{Conclusions}

The classification bears a clear resemblance to the traditional distinction made in continental Civil Law between legal persons (juristische Personen, personnes juridiques, persone giuridiche), obligations (Schuldverhätnisse, obligations, obbligazioni), and property (Sachen, biens, beni). This resemblance gives support to the hypothesis that legal institutions are, in their origin, images that human beings superimpose on reality. In this connection it is interesting to see that Samuel Pufendorf drew a distinction between entia physica and entia moralia, the latter being forms superimposed on nature in order to specify and constrain human acts of will and to bring order in human life. Where divine creation is the source of the existence of physical entities, human impositio is the source of the existence of moral entities (Sève 1990, 312-13; Heinz 1992, 112). Pufendorf's distinction is obviously inspired by a notion of legal institutions as, so to speak, a kind of "reversed description."

Like the exposition of terms used to convey theoretical information that was taken as a point of departure, the classification is a simplification. In these concluding remarks, I shall invite attention to two important complicating factors.

The first factor was already touched upon when legal objects were characterized as valid presentations of the "transactionability" of institutions. The characteristic implies that legal objects are actually valid presentations of a property of valid presentations. What we see here is that once legal institutions are accepted in the form of valid presentations concerning reality, the next step is to accept legal institutions concerning legal institutions, too- that is, institutions of a second order. And there is no reason to rule out legal institutions of still higher orders. On the contrary, in modern legal orders opportunities for combining legal institutions are so abundant that major social institutions, such as governments, legislative bodies, organizations of private enterprise, social security systems, and the like all rest on intricate complexes of legal institutions of different types and orders. Higherorder institutions occur in a bewildering variety. Here it must suffice to note that legal qualities, the forms of status, and relations can be predicated not only of natural subjects and objects, but also of legal subjects and objects.

The second factor concerns the legal regimes of legal institutions. Notably, such legal regimes are systems of legal rules of various kinds. These rules are partly predetermined by the statutory regulations of the institutional legal 
concepts in question. However, most legal institutions have a legal regime that also includes rules conferring legal powers on certain participants in the respective institution. An institutional legal regime that comprises powerconferring rules is no longer a mere concretization of consequential rules laid down in the statutory regulations of the institutional concept concerned, but actually becomes a relatively independent institutional legal order within a comprehensive legal order. By virtue of their self-regulatory powers, participants are to a certain extent able to design the institutional legal order in accordance with their own wishes. As Hart puts it, by possessing legal powers in the context of a legal institution the individual is turned into a private legislator. "He is made competent to determine the course of the law within the sphere of his contracts, trusts, wills, and other structures of rights and duties which he is enabled to build" (Hart 1961, 40-41).

The idea of higher-order legal institutions together with that of selfregulative institutional legal orders opens up prospects for analyzing legal orders as highly complex over-all systems of rules and roughly corresponding practices that are all reducible to a small number of basic patterns. It is likely that future legal research along these lines will lead to new insights that traditional legal theory, with its focus on the analysis of individual legal rules, cannot provide.

University of Twente
Department of Public Administration
and Public Policy
P.O. Box 217
7500 AE Enschede
The Netherlands

\section{References}

Bengoetxea, Joxerramon. 1991. Institutions, Legal Theory and EC Law. Archiv für Rechts- und Sozialphilosophie 67: 195-213.

Conte, Amedeo G. 1986. Fenomeni di fenomeni. Rivista internazionale di filosofia del diritto 63: 29-57.

Hart, Herbert L. A. 1961. The Concept of Law. Oxford: Oxford University Press.

Heinz, K. E. 1992. Zur Theorie der Rechtlichen Institution. Rechtstheorie 23: 106-22.

MacCormick, Neil, and Ota Weinberger. 1986. An Institutional Theory of Law. Dordrecht: Reidel.

March, James G., and Johan P. Olsen. 1989. Rediscovering Institutions. The Organizational Basis of Politics. New York: Free Press.

Olivecrona, Karl. 1971. Law as Fact. 2nd. ed. London: Stevens.

Ostrom, Elinor. 1986. An Agenda for the Study of Institutions. Public Choice 48: 3-25.

. 1990. Governing the Commons. The Evolution of Institutions for Collective Action. Cambridge, N.Y.: Cambridge University Press.

Ross, Alf. 1958. On Law and Justice. London: Stevens.

Rowe, Nicholas. 1989. Rules and Institutions. Ann Arbor: University of Michigan Press. 
Ruiter, Dick W. P. 1993. Institutional Legal Facts. Legal Powers and Their Effects. Dordrecht: Kluwer.

. 1994. Economic and Legal Institutionalism: What Can They Learn from Each Other? Constitutional Political Economy 1: 99-115.

Searle, John R. 1969. Speech Acts. An Essay in the Philosophy of Language. London: Cambridge University Press.

1979. Expression and Meaning. Studies in the Theory of Speech Acts. Cambridge: Cambridge University Press.

Searle, John R., and Daniel VanderVeken. 1985. Foundations of Illocutionary Logic. Cambridge: Cambridge University Press.

Sève, R. 1990. L'institution juridique: imposition et interpretation. Revue de Métaphysique et de Morale 3: 311-37.

VanderVeken, Daniel. 1990. Meaning and Speech Acts. Cambridge: Cambridge University Press.

Weinberger, Ota. 1991. Law, Institution and Legal Politics. Dordrecht: Kluwer.

Wróblewski, Jerzy. 1992. The Judicial Application of Law. Ed. Zenon Bánkowski and Neil MacCormick. Dordrecht: Kluwer. 